\title{
Avaliação de modelos preditivos de conforto térmico em escritórios no clima subtropical brasileiro
}

\author{
Assessment of predictive models of thermal comfort in \\ offices in the Brazilian subtropical climate
}

\section{Ricardo Forgiarini Rupp \\ Enedir Ghisi}

\section{Resumo}

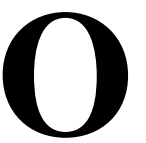

objetivo deste trabalho é comparar as respostas subjetivas de usuários de escritórios localizados no clima subtropical brasileiro, ao longo das quatro estações climáticas, com os modelos de conforto térmico (analítico e adaptativo) da ASHRAE 55 (2017). Estudos de campo sobre conforto térmico foram realizados em quatro edificações de escritórios em Florianópolis/SC durante dois anos. Uma das edificações operou com sistema de ar-condicionado central, enquanto as demais edificações operaram com ventilação híbrida (usuários controlaram o sistema de ar-condicionado e a operação de aberturas). Questionários de conforto térmico foram aplicados, ao mesmo tempo e no mesmo espaço, em que medições das variáveis ambientais (temperatura do ar, umidade relativa, temperatura radiante média e velocidade do ar) foram realizadas. Mais de 7.500 respostas dos usuários foram coletadas durante os estudos de campo, as quais foram comparadas com os modelos da ASHRAE 55. O modelo analítico superestimou as sensações de frio e de calor dos usuários e também não estimou adequadamente a porcentagem de insatisfeitos em todas as estações climáticas e edificações. Durante a operação da ventilação natural, os usuários das edificações com ventilação híbrida se adaptaram às variações térmicas internas de acordo com o modelo de conforto térmico adaptativo.

Palavras-chave: Ventilação híbrida. PMV. Modelo adaptativo. Estudo de campo.

${ }^{1}$ Ricardo Forgiarini Rupp

${ }^{1}$ Universidade Federal de Santa Catarina Florianópolis - SC - Brasil

${ }^{2}$ Enedir Ghisi ${ }^{2}$ Universidade Federal de Santa Florianópolis - SC - Brasil

Recebido em 07/05/18 Aceito em 27/07/18

\begin{abstract}
The objective of this study is to compare the subjective responses of office users located in the Brazilian subtropical climate over the four seasons, using ASHRAE 55 (2017) thermal comfort models (both analytical and adaptive). Field studies on thermal comfort were carried out in four office buildings in Florianópolis/Brazil for two years. One of the buildings operated with central air-conditioning system, while the other buildings operated with hybrid ventilation (users controlled the air-conditioning system and the operation of openings). Thermal comfort questionnaires were applied at the same time and in the same space in which measurements of the environmental variables (air temperature, relative humidity, mean radiant temperature and air velocity) were performed. More than 7,500 user responses were collected during the field study and compared to the ASHRAE 55 models. The analytical model overestimated users' cold and warm sensations and did not adequately estimate the percentage of dissatisfied users in all seasons and buildings. During the natural ventilation operation, users of buildings with hybrid ventilation adapted to the indoor thermal variations according to the adaptive thermal comfort model.

Keywords: Hybrid ventilation. PMV. Adaptive model. Field study.
\end{abstract}




\section{Introdução}

A norma americana ASHRAE 55 (AMERICAN..., 2017) é referência internacional quando se trata da avaliação de conforto térmico em espaços internos. Desde 2004 (AMERICAN..., 2004), esta norma apresenta dois procedimentos de avaliação (AMERICAN..., 2017). O primeiro é baseado no clássico modelo analítico de Fanger (1970), por meio dos índices PMV (Predicted Mean Vote ou Voto Médio Estimado) e PPD (Predicted Percentage of Dissatisfied ou Porcentagem Predita de Insatisfeitos), derivados de experimentos em câmaras climáticas. O PMV tem como objetivo predizer a sensação térmica média de um grupo de pessoas e a respectiva porcentagem predita de insatisfeitos (PPD) com o ambiente térmico. Fanger (1970) estabeleceu como condições aceitáveis aquelas nas quais o PMV varia entre $-1,0$ e $+1,0$. Porém, a ASHRAE 55 restringiu as condições aceitáveis a uma faixa de variação do PMV entre 0,5 e $+0,5$. Esta estreita faixa de variação térmica impacta diretamente no consumo de energia em sistemas de ar-condicionado e não necessariamente garante melhores condições de conforto térmico (HOYT et al., 2009; ARENS et al., 2010).

O segundo procedimento de avaliação da ASHRAE 55 (AMERICAN..., 2017) utiliza os fundamentos da teoria de conforto térmico adaptativo, baseada em estudos de campo em edificações, que relaciona a temperatura de conforto interna em função da temperatura do ar externo (DE DEAR; BRAGER, 1998; HUMPHREYS; NICOL, 1998; NICOL; HUMPHREYS, 2002, 2010; HUMPHREYS; RIJAL; NICOL, 2013). De acordo com a ASHRAE 55 (AMERICAN..., 2017), o modelo analítico deve ser utilizado para avaliar o conforto térmico em qualquer tipo de ambiente (condicionado artificialmente ou não). O modelo adaptativo está restrito a edificações ventiladas naturalmente sem sistema de ar-condicionado instalado. Sendo assim, as edificações com ventilação híbrida, onde há alternância entre o sistema de ar-condicionado e a operação de janelas, deveriam ser avaliadas pelo modelo analítico.

O modelo analítico de Fanger tem sido estudado quanto à sua adequabilidade para aplicação em edificações reais localizadas em diferentes climas e com populações distintas. Com a emergência da teoria de conforto térmico adaptativo, diversas limitações quanto à adequabilidade do modelo PMV/PPD para aplicação em edificações ventiladas naturalmente foram discutidas na literatura (HUMPHREYS; NICOL, 2002; VAN HOOF, 2008; DEUBLE; DE DEAR, 2012; RUPP; VÁSQUEZ; LAMBERTS, 2015). Porém, estudos também apontaram diferenças entre as respostas subjetivas dos usuários e as preditas pelo modelo de Fanger em edificações operando com sistema de arcondicionado em Taiwan (HWANG et al., 2009), na Malásia (DAGHIGH; SOPIAN, 2009), na Bélgica (HENS, 2009), em Hong Kong (FONG; CHOW; LI, 2010), na China (CAO et al., 2011), na Itália (RICCIARDI; BURATTI, 2012) e na Índia (MAITI, 2013, 2014). No estudo em Taiwan, as porcentagens real e predita de insatisfeitos diferiram em mais de 10\% (HWANG et al., 2009) e no estudo na Bélgica a diferença foi superior a $5 \%$ (HENS, 2009). Em condições de neutralidade térmica e em temperaturas mais elevadas, o PMV superestimou a sensação térmica das pessoas na Índia (MAITI, 2014). Durante o verão e o inverno em escritórios na Itália (RICCIARDI; BURATTI, 2012) e em salas de aula e escritórios na China (CAO et al., 2011), o PMV superestimou tanto a sensação de frio das pessoas quanto a de calor.

Alguns trabalhos brasileiros compararam as respostas subjetivas de usuários, obtidas por meio de estudos de campo sobre conforto térmico, com o modelo analítico (LAMBERTS et al., 2013; VECCHI, 2015; RUPP; GHISI, 2017). Um desses trabalhos revisou estudos de campo e apontou para limitações do modelo PMV/PPD para aplicação no contexto brasileiro, principalmente em climas quentes e úmidos (LAMBERTS et al., 2013). Outros estudos comparativos entre o modelo analítico e as respostas dos usuários foram realizados em edificações de escritórios com sistema de ar-condicionado central e em edificações com ventilação híbrida, localizadas em Florianópolis/SC (VECCHI, 2015; RUPP et al., 2017; RUPP; GHISI, 2017): o modelo PMV superestimou a sensação de frio dos usuários e não estimou adequadamente a porcentagem de insatisfeitos termicamente. Vecchi (2015) e Rupp e Ghisi (2017) também analisaram o modelo adaptativo de conforto térmico da ASHRAE 55 e concluíram que este pode ser utilizado nas edificações com ventilação híbrida. Rupp e Ghisi (2017) encontraram forte correlação entre a temperatura de conforto e as temperaturas externas durante a operação da ventilação natural, porém, indicaram que os usuários toleraram menores temperaturas que as preditas pelo modelo adaptativo. Contudo, cabe ressaltar que os estudos de campo de Vecchi (2015) e Rupp e Ghisi (2017) foram realizados somente durante o outono e o inverno. Dessa maneira, os resultados são limitados a menores temperaturas externas. Portanto, estudos comparativos entre o modelo analítico e resultados de estudos de campo sobre conforto térmico deveriam ser realizados no clima subtropical úmido 
brasileiro, considerando todas as estações climáticas.

O objetivo deste trabalho é comparar as respostas subjetivas de usuários de escritórios localizados no clima subtropical brasileiro, ao longo das quatro estações climáticas, com os métodos analítico e adaptativo da ASHRAE 55 (AMERICAN..., 2017).

\section{Método}

Este trabalho é baseado em estudos de campo em edificações de escritórios localizadas em Florianópolis/SC. Medições das variáveis ambientais (temperatura do ar, de globo, umidade relativa e velocidade do ar) foram realizadas ao mesmo tempo e no mesmo ambiente em que usuários respondiam a questionários eletrônicos de conforto térmico. A temperatura horária do ar externo foi obtida da estação meteorológica do INMET (Florianópolis). Os dados foram coletados em diversos dias entre março de 2014 e março de
2016, considerando as diferentes estações climáticas.

As respostas subjetivas dos usuários às condições térmicas foram comparadas com os modelos analítico e adaptativo da norma americana ASHRAE 55 (AMERICAN..., 2017).

\section{Edificações de escritório}

Quatro edificações de escritórios foram estudadas em Florianópolis/SC. Uma das edificações operou com sistema de ar-condicionado central. Nesta edificação os usuários não podiam operar as janelas, pois estas eram seladas. As outras três edificações operaram com ventilação híbrida (os usuários controlaram a mudança entre a ventilação natural através das aberturas e o uso do sistema de arcondicionado para resfriamento). As características das edificações estudadas são apresentadas na Tabela 1.

Tabela 1 - Características das edificações com ventilação híbrida e com sistema de ar-condicionado central

\begin{tabular}{|c|c|c|c|c|}
\hline $\begin{array}{c}\text { Identificação da } \\
\text { edificação }\end{array}$ & H1 & $\mathbf{H} 2$ & H3 & AVAC \\
\hline Modo de operação & $\begin{array}{l}\text { Ventilação } \\
\text { híbrida }\end{array}$ & $\begin{array}{l}\text { Ventilação } \\
\text { híbrida }\end{array}$ & $\begin{array}{l}\text { Ventilação } \\
\text { híbrida }\end{array}$ & $\begin{array}{l}\text { Sistema de ar- } \\
\text { condicionado } \\
\text { central } \\
\end{array}$ \\
\hline \multicolumn{5}{|c|}{ Características construtivas e ambientes internos } \\
\hline Ano de construção & Década de 1990 & Década de 1990 & Década de 1990 & 1979 \\
\hline Ano da última reforma & - & - & 2012 & 2008 \\
\hline Área construída $\left(\mathrm{m}^{2}\right)$ & 6200 & 8244 & 3090 & 27432 \\
\hline Número de blocos & 3 & 1 & 1 & 1 \\
\hline Número de pavimentos & 1,1 e 2 & 12 & 5 & 5 \\
\hline $\begin{array}{l}\text { Ambientes de } \\
\text { escritórios }\end{array}$ & $\begin{array}{c}\text { Planta livre com } \\
\text { divisórias } \\
\text { internas } \\
\end{array}$ & $\begin{array}{c}\text { Planta livre com } \\
\text { divisórias } \\
\text { internas } \\
\end{array}$ & $\begin{array}{c}\text { Planta livre com } \\
\text { divisórias } \\
\text { internas } \\
\end{array}$ & $\begin{array}{c}\text { Planta livre com } \\
\text { divisórias } \\
\text { internas } \\
\end{array}$ \\
\hline $\begin{array}{l}\text { Altura do pé-direito } \\
(\mathrm{m})\end{array}$ & 2,6 & 2,6 & 2,6 & 2,5 \\
\hline Operação das janelas & $\begin{array}{c}\text { Janelas operáveis } \\
\text { pelos usuários }\end{array}$ & $\begin{array}{c}\text { Janelas operáveis } \\
\text { pelos usuários }\end{array}$ & $\begin{array}{c}\text { Janelas operáveis } \\
\text { pelos usuários }\end{array}$ & Janelas seladas \\
\hline $\begin{array}{l}\text { Sistema de ar- } \\
\text { condicionado }\end{array}$ & Split & Split & Split & Central \\
\hline $\begin{array}{l}\text { Operação da ventilação } \\
\text { híbrida }\end{array}$ & $\begin{array}{c}\text { Controle } \\
\text { realizado pelos } \\
\text { usuários }\end{array}$ & $\begin{array}{c}\text { Controle } \\
\text { realizado pelos } \\
\text { usuários }\end{array}$ & $\begin{array}{c}\text { Controle } \\
\text { realizado pelos } \\
\text { usuários }\end{array}$ & Não disponível \\
\hline \multicolumn{5}{|c|}{ Questionários } \\
\hline Número de ocupantes & 320 & 350 & 250 & 1200 \\
\hline Horário de ocupação & $8: 00-18: 00$ & 13:00 -19:00 & $8: 00-18: 00$ & $7: 00-19: 00$ \\
\hline $\begin{array}{l}\text { Número de } \\
\text { questionários }\end{array}$ & 1567 & 582 & 3321 & 2094 \\
\hline
\end{tabular}


Todos os ambientes de escritório estudados eram do tipo planta livre com divisórias internas. Nenhuma das edificações possuía aquecimento artificial. Em todas as edificações somente os ambientes de trabalho com atividades de escritório foram considerados. Os halls de acesso, as recepções, as salas de reuniões, os banheiros, as copas, os depósitos, as circulações internas e outros ambientes transitórios foram desconsiderados. Nas edificações com ventilação híbrida, todos os ambientes estudados possuíam janelas acessíveis e operáveis pelos usuários, permitindo a entrada direta do ar externo.

Maiores informações sobre as edificações podem ser encontradas em Rupp (2018). As informações das edificações são sigilosas, por isso não são apresentadas plantas e afins, pois não são necessárias para alcançar os objetivos deste trabalho.

\section{Estudos de campo}

Os estudos de campo envolveram a participação voluntária de usuários das edificações de escritórios por meio de um questionário de conforto térmico. O questionário eletrônico incluiu questões sobre os dados antropométricos e outras características individuais dos usuários (vestimenta e atividade metabólica), sensação, preferência, aceitabilidade térmica e conforto térmico (Tabela 2). A vestimenta e a atividade metabólica foram estimadas com base nas respostas dos usuários, conforme a ASHRAE 55.

O aplicativo contendo o questionário foi enviado aos participantes da pesquisa por meio de e-mail, dispositivo de memória ou disponibilizado na rede interna de cada edificação. Somente os usuários presentes em cada ambiente, no momento de cada estudo de campo, podiam ter acesso ao aplicativo.
Uma vez executado o aplicativo, as perguntas apareciam automaticamente na tela do computador para serem respondidas pelos usuários.

As condições térmicas internas (temperatura do ar, umidade relativa, temperatura de globo e velocidade do ar) foram monitoradas por meio de estações microclimáticas SENSU, desenvolvidas e calibradas pelo Laboratório de Meios Porosos e Propriedades Termofísicas da Universidade Federal de Santa Catarina (Figura 1). Também foram utilizados termoanemômetros portáteis (marca AirFlow - modelo TA35) para medições pontuais de temperatura e velocidade do ar (Figura 2). As medições foram realizadas de acordo com os procedimentos recomendados pela ASHRAE 55.

Durante todo o período de medição ambiental os pesquisadores observaram continuamente o comportamento dos usuários (operação de aberturas e/ou sistema de ar-condicionado, mudança de vestimenta, alteração do metabolismo). Estas informações comportamentais foram registradas em planilhas.

\section{Análises dos dados}

Os dados ambientais coletados foram cruzados em planilhas eletrônicas com as respostas subjetivas dos usuários. Estes dados foram comparados com os modelos analítico e adaptativo da ASHRAE 55 (AMERICAN..., 2017).

A temperatura operativa interna $\left(\mathrm{T}_{0}\right)$ e a temperatura média predominante do ar externo ( $\left.\mathrm{T}_{\text {pma(out) }}\right)$ foram calculadas conforme a ASHRAE 55 (AMERICAN..., 2017). Os valores de PMV e PPD foram calculados no programa R (2017) usando os scripts desenvolvidos por Silva, Ghisi e Lamberts (2016).

Tabela 2 - Perguntas e opções de respostas aos questionários de conforto térmico

\begin{tabular}{l|c|c|c|c|c|c|c}
\hline \multirow{2}{*}{ Descrição da escala } & \multicolumn{7}{|c}{ Valor na escala } \\
\cline { 2 - 7 } Sensação térmica & $\mathbf{- 3}$ & $\mathbf{- 2}$ & $\mathbf{- 1}$ & $\mathbf{0}$ & $\mathbf{1}$ & $\mathbf{2}$ & $\mathbf{3}$ \\
\hline Preferência térmica & $\begin{array}{c}\text { Com } \\
\text { frio }\end{array}$ & Com frio & $\begin{array}{c}\text { Leve- } \\
\text { mente } \\
\text { frio }\end{array}$ & Neutro & $\begin{array}{c}\text { Leve- } \\
\text { mente } \\
\text { calor }\end{array}$ & $\begin{array}{c}\text { Com } \\
\text { calor }\end{array}$ & $\begin{array}{c}\text { Com } \\
\text { muito } \\
\text { calor }\end{array}$ \\
\hline Aceitabilidade térmica & - & - & $\begin{array}{c}\text { Mais } \\
\text { resfriado }\end{array}$ & $\begin{array}{c}\text { Assim } \\
\text { mesmo }\end{array}$ & $\begin{array}{c}\text { Mais } \\
\text { aquecido }\end{array}$ & - & - \\
\hline Conforto térmico & - & - & - & Aceitável & $\begin{array}{c}\text { Inacei- } \\
\text { tável }\end{array}$ & - & - \\
\hline
\end{tabular}




\section{Figura 1 - Estação microclimática SENSU}

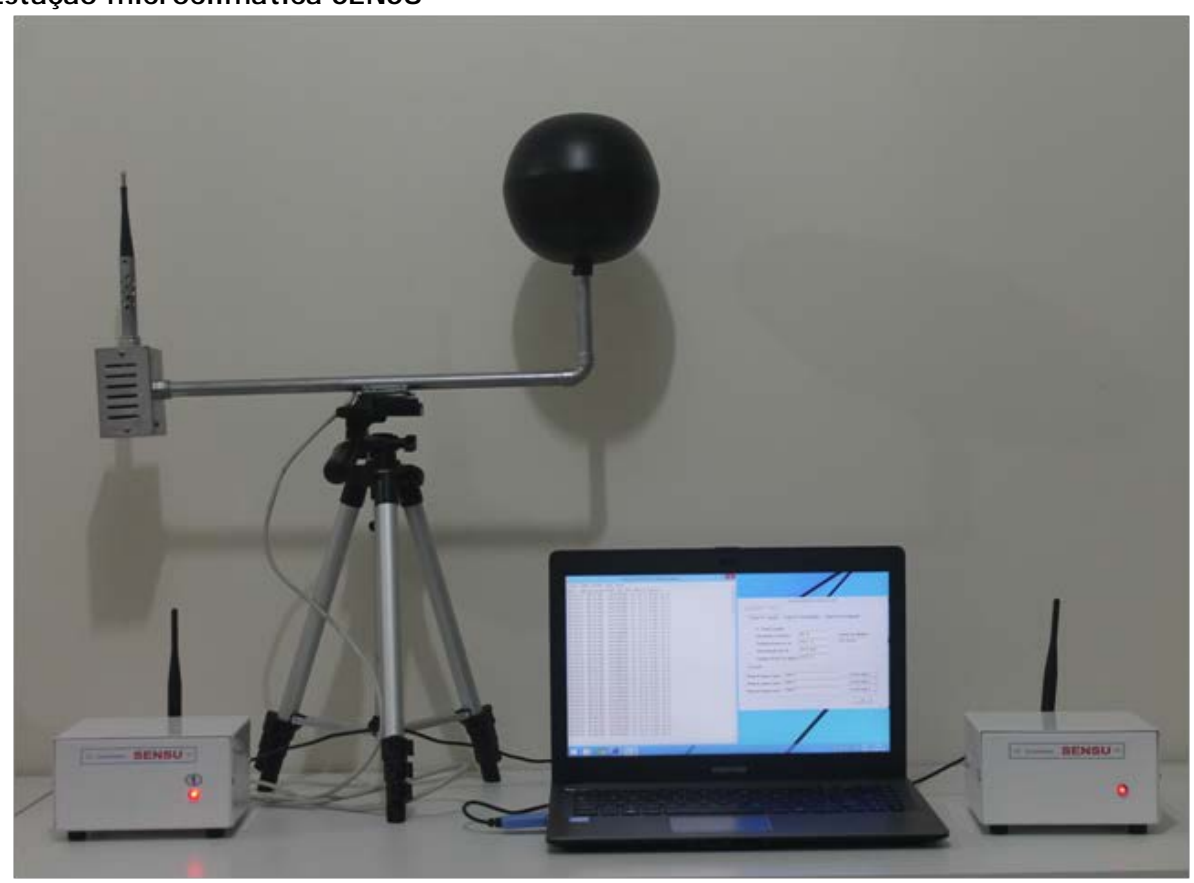

Figura 2 - Termoanemômetro portátil AirFlow

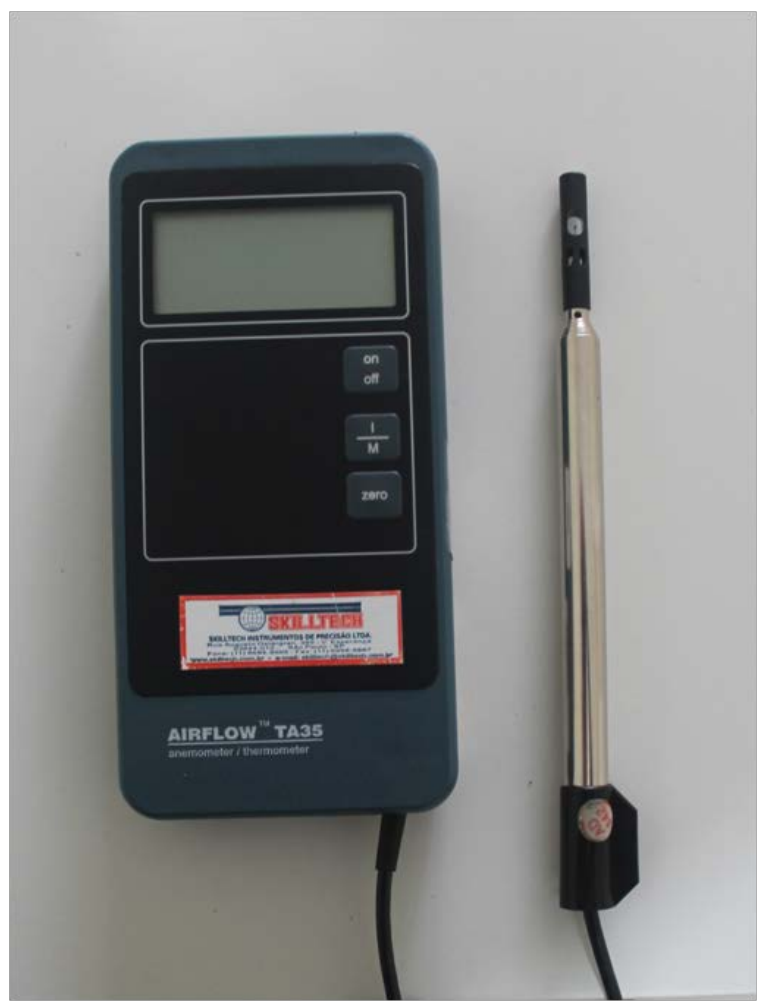

\section{Resultados}

Como resultados dos estudos de campo foram coletadas 7.564 respostas subjetivas dos usuários associadas às variáveis ambientais. Os estudos foram realizados em diversos dias, durante os horários de ocupação das edificações, nas diferentes estações climáticas, conforme mostrado nas Figuras 3 e 4, que também apresentam o modo de operação e isolamento da vestimenta na edificação com sistema de ar-condicionado central e nas edificações com ventilação híbrida. 
Figura 3 - Modo de operação, isolamento da vestimenta e período de realização de cada estudo de campo na edificação com sistema de ar-condicionado central

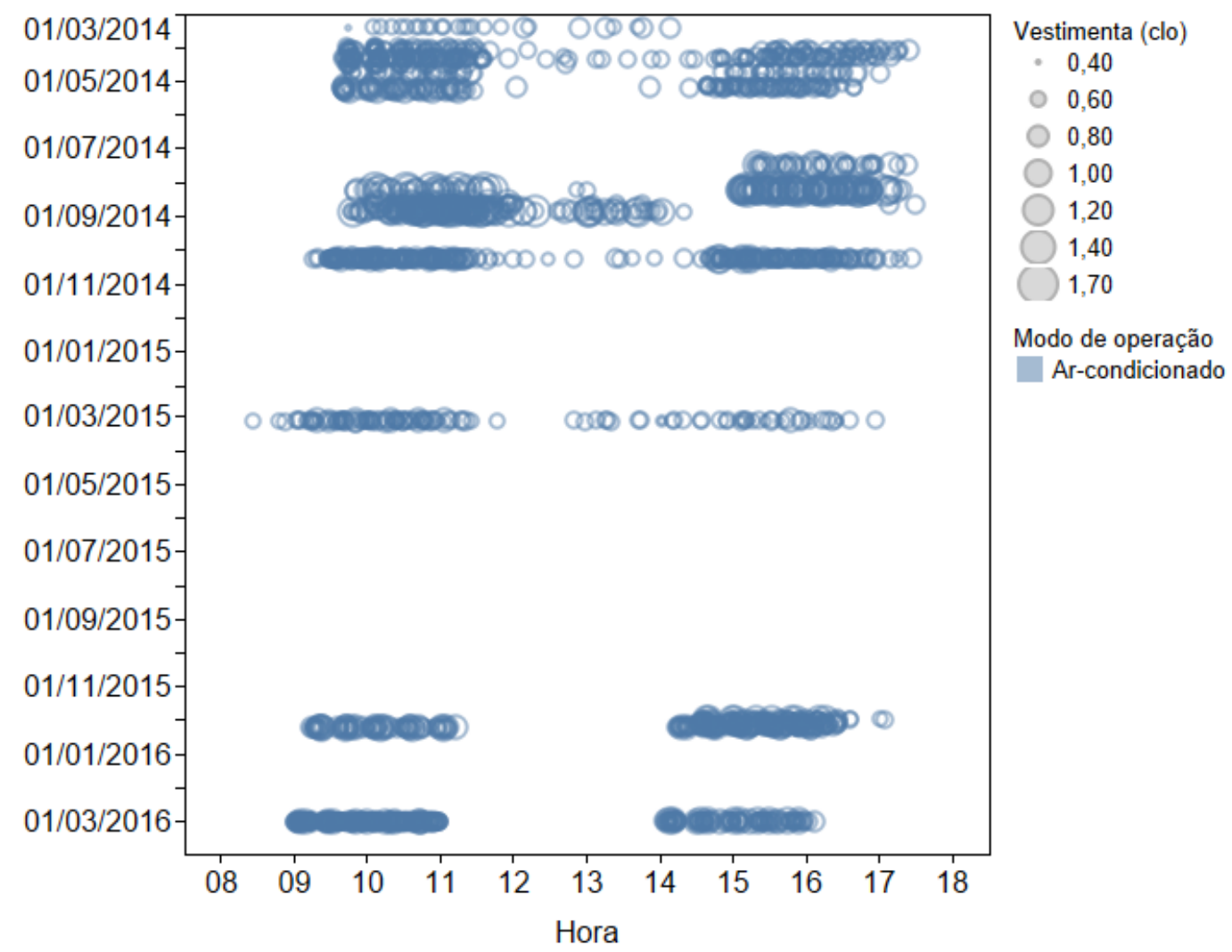

Figura 4 - Modo de operação, isolamento da vestimenta e período de realização de cada estudo de campo nas edificações com ventilação híbrida

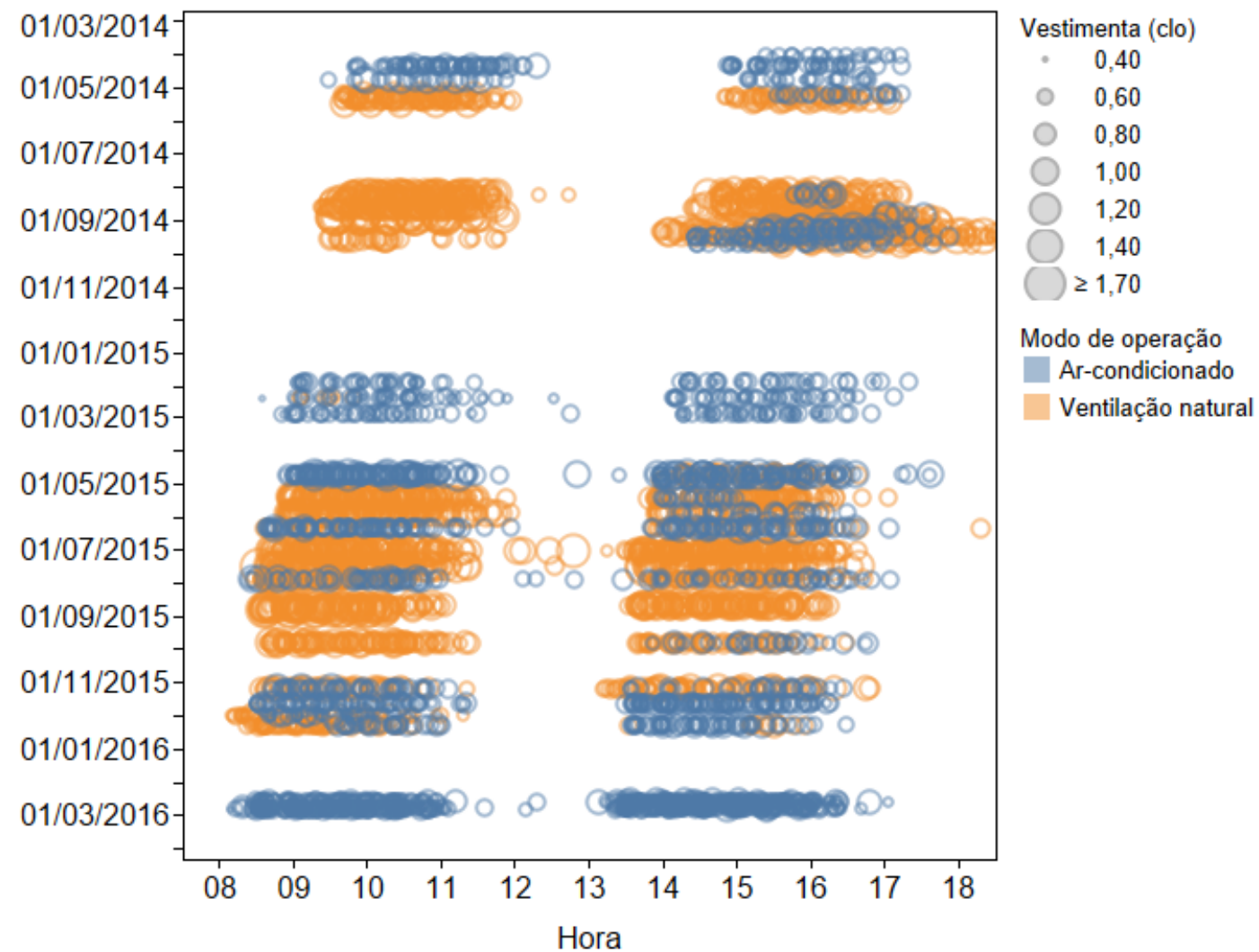




\section{Usuários, condições térmicas e respostas subjetivas}

A Tabela 3 apresenta um resumo das variáveis humanas por tipo de ventilação da edificação. Um resumo das condições térmicas e das respostas subjetivas dos usuários durante os estudos de campo pode ser encontrado na Tabela 4. As Figuras 5 e 6 apresentam as respostas de sensação térmica dos usuários, de acordo com a temperatura operativa interna e a temperatura média predominante do ar externo, para a edificação com sistema de arcondicionado central e para as edificações com ventilação híbrida, respectivamente.

Em todas as edificações uma amostra heterogênea de pessoas participou do estudo. Os usuários das edificações desempenharam atividades típicas de escritórios (1,0 a 1,4 met) e suas vestimentas variaram conforme as diferentes estações climáticas entre 0,41 e 1,4clo (Tabela 3 e Figuras 3 e 4). A Tabela 3 também apresenta as características antropométricas dos participantes, separadas por tipo de ventilação da edificação - sistema de arcondicionado (AC) central ou híbridos.

As condições térmicas médias internas foram similares entre as diferentes edificações (Tabela 4). De modo geral, a maioria dos usuários sentiram-se "neutros", prefeririam continuar sentindo-se como estavam ("assim mesmo"), aceitaram o ambiente térmico e reportaram estar em conforto térmico.

Como pode ser observado na Figura 5, os usuários da edificação com sistema de ar-condicionado central estiveram expostos a uma faixa estreita de temperaturas internas nas diferentes estações climáticas. Apesar disso, as pessoas reportaram diversas sensações térmicas, demonstrando as diferenças existentes devido à subjetividade dos indivíduos.

Tabela 3 - Resumo das variáveis humanas por tipo de ventilação da edificação.

\begin{tabular}{l|l|c|c|c|c|c|c}
\hline Tipo de ventilação & Parâmetro & $\begin{array}{c}\text { Idade } \\
\text { (anos) }\end{array}$ & $\begin{array}{c}\text { Peso } \\
(\mathbf{k g})\end{array}$ & $\begin{array}{c}\text { Altura } \\
(\mathbf{m})\end{array}$ & $\begin{array}{c}\text { IMC } \\
\left(\mathbf{k g} / \mathbf{m}^{2}\right)\end{array}$ & $\begin{array}{c}\text { Vestimenta } \\
(\mathbf{c l o})\end{array}$ & $\begin{array}{c}\text { Metabolismo } \\
\text { (met) }\end{array}$ \\
\hline \multirow{3}{*}{ AC central (n=2094) } & Média & 39,0 & 75,3 & 1,72 & 25,3 & 0,66 & 1,1 \\
& Desv. Pad. & 11,1 & 15,1 & 0,10 & 3,7 & 0,14 & 0,1 \\
& Máximo & 74,0 & 135 & 1,97 & 41,7 & 1,40 & 1,4 \\
& Mínimo & 16,0 & 40 & 1,50 & 16,9 & 0,41 & 1,0 \\
\hline \multirow{3}{*}{ Híbridos (n=5470) } & Média & 38,3 & 73,9 & 1,70 & 25,5 & 0,69 & 1,1 \\
& Desv. Pad. & 11,0 & 15,6 & 0,10 & 4,2 & 0,19 & 0,1 \\
& Máximo & 81,0 & 170 & 1,97 & 64 & 1,73 & 1,4 \\
& Mínimo & 15,0 & 43 & 1,48 & 16,9 & 0,41 & 1,0 \\
\hline
\end{tabular}

Tabela 4 - Resumo das condições térmicas e respostas subjetivas dos usuários durante os estudos de campo

\begin{tabular}{|c|c|c|c|c|}
\hline \multicolumn{2}{|c|}{ Tipo de ventilação } & \multirow{3}{*}{$\frac{\text { AC central }}{(n=2094)}$} & \multicolumn{2}{|c|}{ Híbridos } \\
\hline \multirow{2}{*}{\multicolumn{2}{|c|}{ Variável (média) }} & & \multicolumn{2}{|c|}{ Modo de operação } \\
\hline & & & VN (n=3121) & $\mathrm{AC}(\mathrm{n}=2349)$ \\
\hline \multirow{3}{*}{ Condições internas } & $\mathrm{T}_{\mathrm{o}}\left({ }^{\circ} \mathrm{C}\right)$ & 23,3 & 23,5 & 24,2 \\
\hline & $\mathrm{V}_{\mathrm{ar}}(\mathrm{m} / \mathrm{s})$ & 0,12 & 0,13 & 0,12 \\
\hline & UR (\%) & 62 & 65 & 59 \\
\hline Condições externas & $\mathrm{T}_{\text {pma(out) }}\left({ }^{\circ} \mathrm{C}\right)$ & 21,6 & 19,0 & 22,9 \\
\hline \multirow{2}{*}{ Variáveis humanas } & Metabolismo (met) & 1,1 & 1,1 & 1,1 \\
\hline & Vestimenta (clo) & 0,66 & 0,75 & 0,60 \\
\hline \multirow{4}{*}{$\begin{array}{l}\text { Respostas subjetivas } \\
\text { (térmicas) }\end{array}$} & Sensação (AMV) & $-0,2$ & 0,0 & 0,0 \\
\hline & Preferência & 0,0 & 0,0 & 0,0 \\
\hline & Aceitabilidade & 0,1 & 0,0 & 0,1 \\
\hline & Conforto & 0,1 & 0,1 & 0,2 \\
\hline \multirow{2}{*}{ Índices } & PMV & $-0,4$ & 0,0 & $-0,1$ \\
\hline & PPD (\%) & 13 & 12 & 11 \\
\hline
\end{tabular}


Figura 5 - Votos de sensação térmica com a correspondente temperatura operativa interna e a temperatura média predominante do ar externo na edificação com sistema de ar-condicionado central

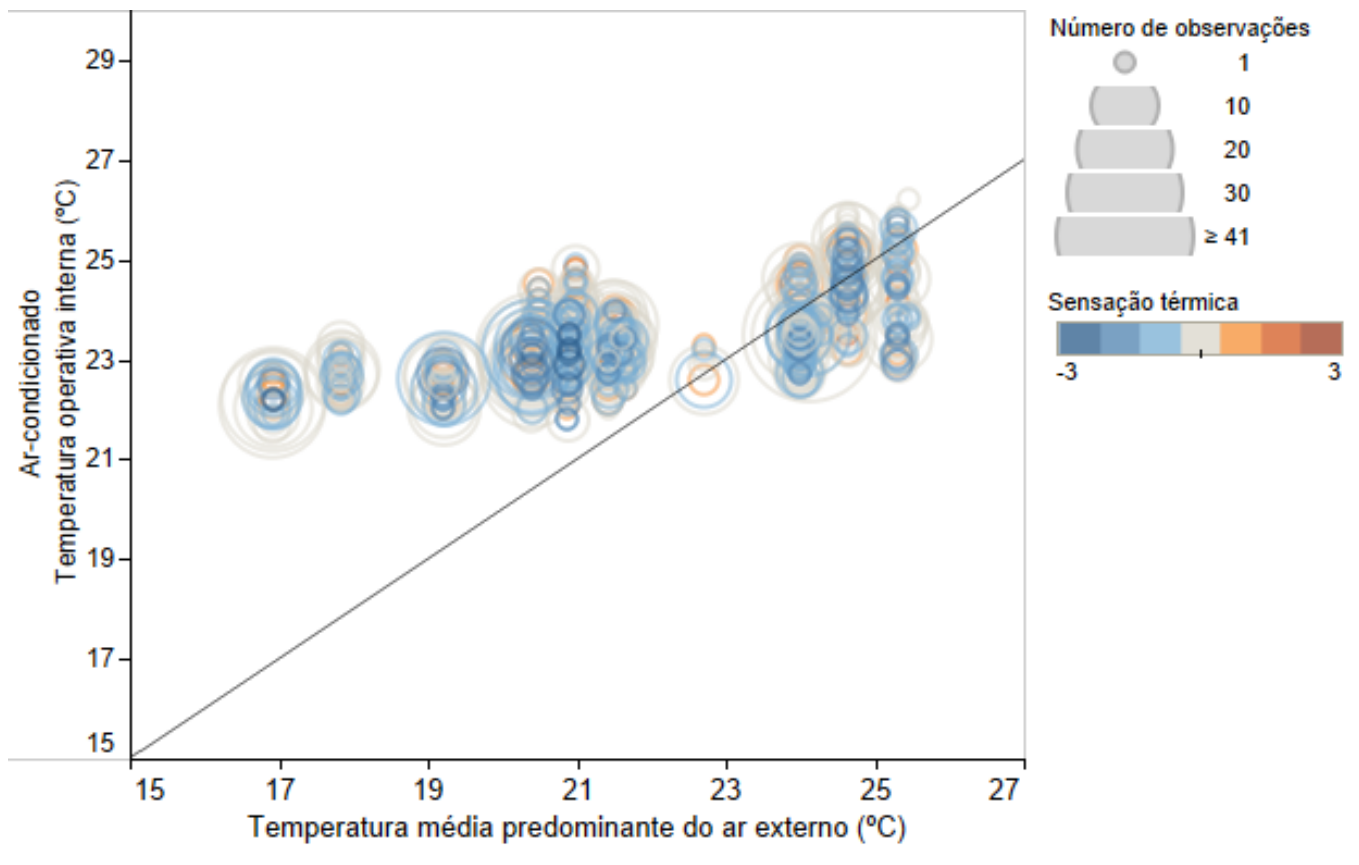

Figura 6 - Votos de sensação térmica separados por modo de operação com a correspondente temperatura operativa interna e a temperatura média predominante do ar externo nas edificações com ventilação híbrida

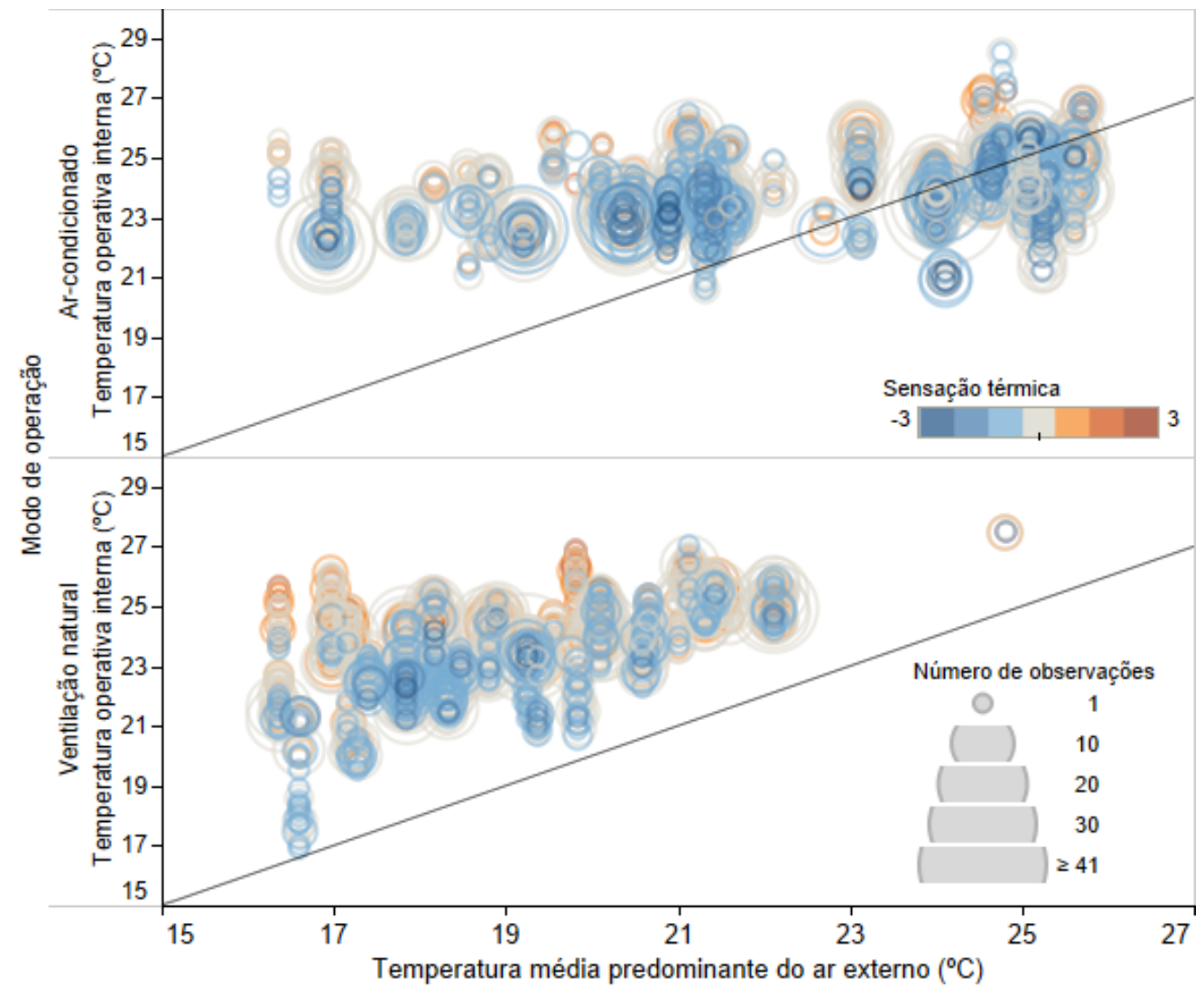


Analisando as edificações com ventilação híbrida percebe-se que a ventilação natural foi utilizada principalmente nas estações mais frias (Figuras $4 \mathrm{e}$ 6 e Tabela 4). Dessa maneira, a temperatura operativa interna foi inferior durante este modo de operação e o isolamento da vestimenta foi superior (os usuários adaptaram-se às diversas condições térmicas por meio do ajuste da vestimenta). Por outro lado, o sistema de ar-condicionado foi acionado pelos usuários em temperaturas mais elevadas e as temperaturas internas oscilaram em uma faixa maior do que na edificação com sistema de ar-condicionado central (Figuras 5 e 6).

\section{Comparação entre os votos médios de sensação térmica preditos e dos usuários}

De modo geral, o PMV superestimou as sensações de frio e de calor dos usuários, tendendo mais para os lados negativo e positivo da escala sétima de sensação térmica.

\section{Edificação com sistema de ar-condicionado central}

A correlação entre PMV e AMV (Actual Mean Vote ou Voto Médio Real) de cada estudo de campo resultou em um coeficiente de determinação $\left(R^{2}\right)$ de 0,06 e a maioria dos pontos ficaram localizados acima ou abaixo da bissetriz (linha que representa uma combinação perfeita entre o PMV e o AMV) (Figura 7). A Figura 7 também apresenta a faixa de condições térmicas aceitáveis pela ASHRAE 55 (PMV $\pm 0,5$ ); pode-se perceber que somente $68 \%$ dos casos estudados atendem à norma. Entretanto, na maioria das situações (92\% dos casos estudados) os valores de AMV variaram entre $-0,5$ e +0,5 Considerando os três pontos centrais da escala de sete pontos de sensação térmica (PMV igual a -1, 0 ou +1) como condições aceitáveis, conforme proposto originalmente por Fanger (1970), a aceitabilidade térmica predita é de 100,0\%. Este valor é mais próximo da aceitabilidade térmica real dos usuários (resposta obtida diretamente via questionários), que foi de 94,5\% das respostas.

\section{Edificações com ventilação híbrida}

Nas edificações com ventilação híbrida o PMV superestimou as sensações de frio e de calor das pessoas, com relação às médias de PMV e AMV (Figura 8). A correlação entre o PMV e o AMV obtida em cada estudo de campo resultou em $\mathrm{R}^{2}$ de 0,30 e 0,11 para o modo de ar-condicionado e ventilação natural, respectivamente.

Durante a operação do ar-condicionado, as temperaturas internas variaram menos, em comparação com os períodos com ventilação natural. Considerando as condições térmicas aceitáveis pela ASHRAE 55, a aceitabilidade térmica predita foi de 78,4\% durante a operação do ar-condicionado e de $72,8 \%$ durante o uso da ventilação natural. Considerando os três pontos centrais da escala de sete pontos de sensação térmica como condições aceitáveis, a aceitabilidade térmica predita foi de 93,8\% (ar-condicionado) e de 82,1\% (ventilação natural). A aceitabilidade térmica real das pessoas foi de 92,8\% (arcondicionado) e 95,7\% (ventilação natural). Assim, novamente, as estreitas faixas de aceitabilidade da ASHRAE 55 previram condições inaceitáveis, quando, na verdade, elas foram aceitáveis pelos ocupantes. Durante o modo de ar-condicionado, utilizando o critério de $P M V \pm 1,0$, o valor de aceitabilidade predita foi similar à aceitabilidade real.

No estudo de Rupp e Ghisi (2017), os autores concluíram que o PMV superestimou as sensações de frio dos usuários, quando analisados os resultados de estudos de campo durante o inverno e o outono. Dessa maneira, neste trabalho também se efetuou uma comparação entre o PMV e o AMV para cada estação climática (verão, outono, inverno e primavera). Porém, os resultados para as edificações com ventilação híbrida foram similares aos da Figura 8, pois o modo de operação está intimamente relacionado com a estação climática ar-condicionado foi utilizado predominantemente na primavera e no verão; ventilação natural, no outono e inverno (Figura 4). Na edificação com arcondicionado central tampouco se identificou que o PMV superestimou as sensações de frio ou de calor durante determinada estação climática. Na verdade, considerando o banco de dados deste trabalho, em todas as estações climáticas o PMV superestimou tanto os valores de frio quanto de calor dos usuários. Desta maneira, as discrepâncias encontradas entre o $\mathrm{PMV}$ e o AMV provavelmente devem-se às diferenças subjetivas dos usuários.

\section{Analisando cada resposta subjetiva}

Durante a operação da ventilação natural nas edificações com ventilação híbrida, os usuários aceitaram termicamente valores de PMV entre -2,63 e +1,25 (Figura 9a). A Figura 9 apresenta as condições térmicas aceitáveis pelos usuários, expressas pelo PMV em relação às temperaturas operativas internas e às temperaturas médias predominantes do ar externo, em ambientes com sistema de ar-condicionado (os dados de todas as edificações foram agrupados) e com ventilação natural. 
Figura 7 - Correlação entre o voto médio predito (PMV) e o voto médio de sensação térmica das pessoas (AMV) na edificação com sistema de ar-condicionado central - as condições térmicas aceitáveis pela ASHRAE 55 são mostradas em cinza; cada ponto representa a média dos votos em cada estudo de campo

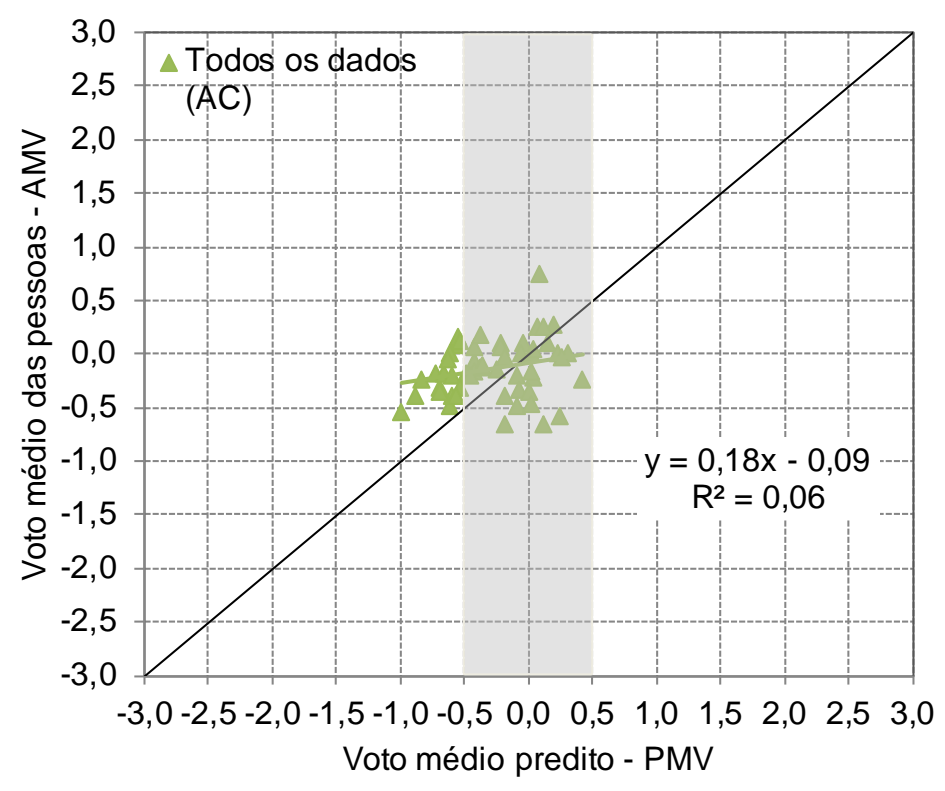

Figura 8 - Correlação entre o voto médio predito (PMV) e o voto médio de sensação térmicas das pessoas (AMV) nas edificações com ventilação híbrida; as condições térmicas aceitáveis pela ASHRAE 55 são mostradas em cinza - cada ponto representa a média dos votos em cada estudo de campo

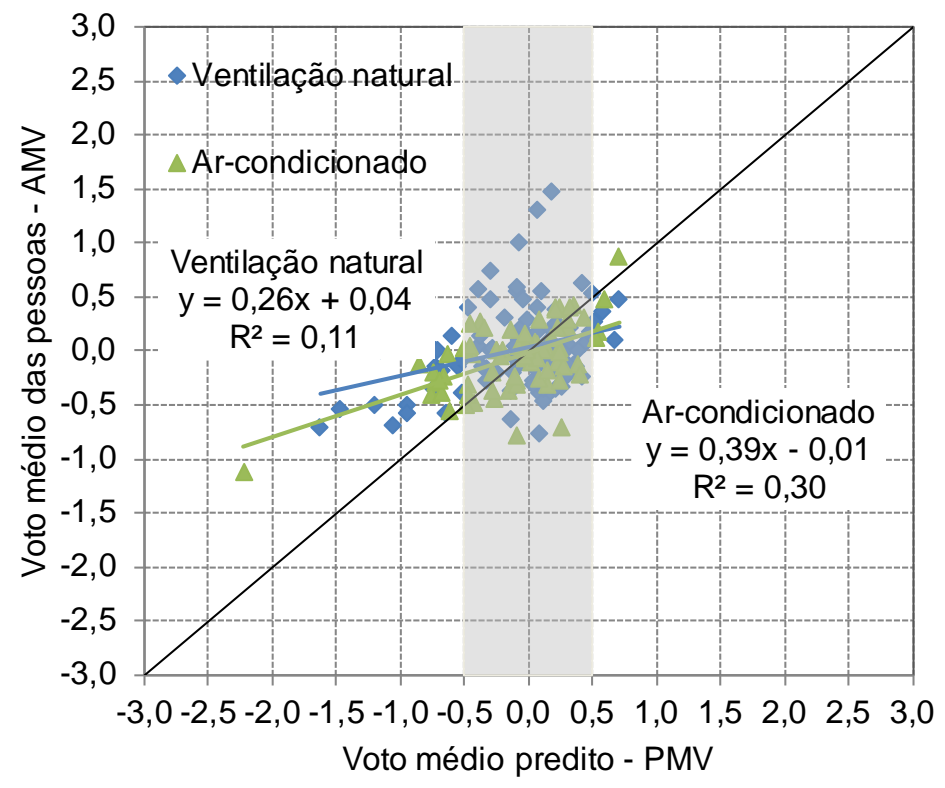


Figura 9 - Condições térmicas aceitáveis expressas pelo PMV para cada modo de operação e relacionadas às condições internas e externas - os dados de todas as edificações estão agrupados

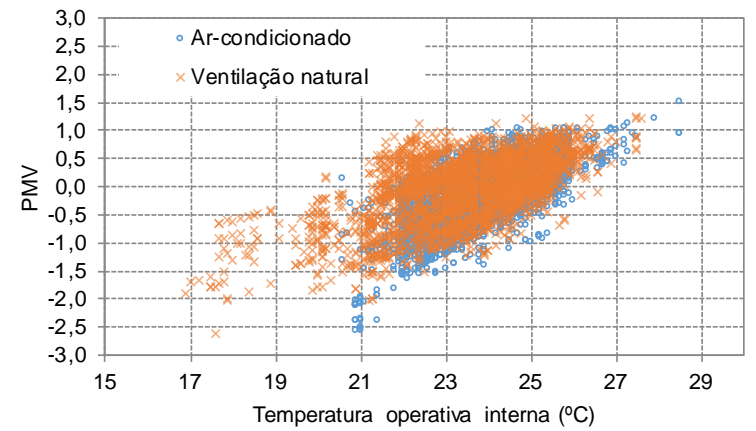

(a) PMV versus temperatura operativa interna

Os usuários de edificações de escritórios quando expostos a ambientes com sistema de arcondicionado aceitaram termicamente valores de PMV entre -2,56 e +1,51 (Figura 9a). Em ambos os modos de operação os usuários aceitaram faixas amplas de condições térmicas internas. Sendo assim, não há evidências para justificar a estreita faixa de PMV (entre $-0,5$ e $+0,5$ ) recomendada pela ASHRAE 55. Além disso, as faixas amplas aceitas termicamente pelos usuários ocorreram nos diferentes intervalos de temperatura média predominante do ar externo, em ambos os modos de operação (Figura 9b).

\section{Comparação entre as porcentagens real e predita de insatisfeitos}

As Figuras 10 e 11 comparam a porcentagem real de pessoas insatisfeitas (APD, Actual Percentage of Dissatisfied) com a porcentagem predita de insatisfeitos (PPD) em função do PMV para cada estudo de campo, para a edificação com sistema de ar-condicionado central e para as edificações híbridas, respectivamente. Na maioria das situações a PPD difere da APD. A média das diferenças entre a PPD e a APD foi de $10 \%$ em todas as edificações. Porém, houve diferenças de até $40 \%$ para a edificação com sistema de ar-condicionado central, de até $52 \%$ para as edificações híbridas no modo de ar-condicionado e de até $58 \%$ para o modo de ventilação natural. Este

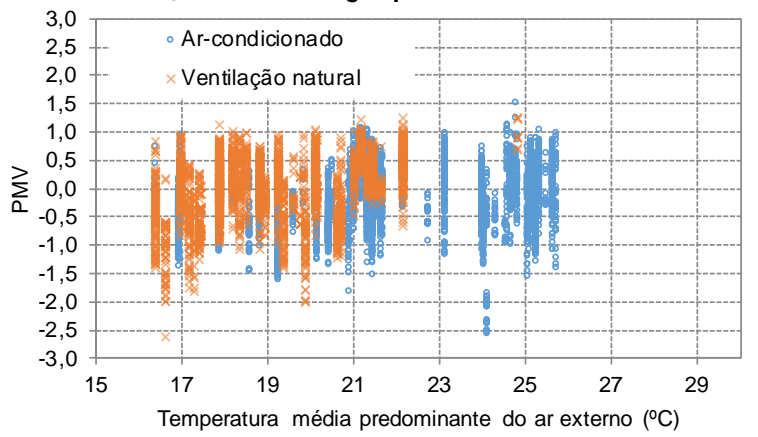

(b) PMV versus temperatura média predominante do ar externo

resultado vai ao encontro de outros trabalhos que compararam PPD e APD no Brasil (LAMBERTS et al., 2013, RUPP; GHISI, 2017), os quais não usaram dados de todas as estações climáticas. Também é interessante notar que em diversas situações APDs de $0 \%$ foram atingidas em diferentes valores de PMV (entre -0,63 e +0,22 para a edificação com sistema de ar-condicionado central; entre $-0,73$ e +0,55 durante a operação do ar-condicionado nas edificações híbridas e entre 1,63 e $+0,21$ durante o uso da ventilação natural).

A Figura 12 apresenta a correlação entre a porcentagem real de pessoas insatisfeitas (APD) e o voto médio de sensação térmica real das pessoas (AMV) para cada modo de operação e para cada estudo de campo. A Figura 12 também mostra a curva PMV/PPD. Durante a operação do arcondicionado, a curva AMV/APD resultante é mais estreita que a curva do PMV/PPD, indicando que menores desvios da neutralidade geram maior desconforto térmico (Figura 12a). Com PMV igual a -1,00, o PPD é aproximadamente $26 \%$. Por outro lado, com AMV igual a -1,00, o APD é de 40\%, valor bem acima do predito pelo modelo de Fanger (1970). Coincidentemente, no intervalo entre -0,5 e $+0,5$, a curva AMV/APD se assemelha à curva PMV/PPD para o modo de ventilação natural (Figura 12b). Entretanto, os valores de $\mathrm{R}^{2}$ foram de apenas 0,29 e 0,17 para ar-condicionado e ventilação natural, respectivamente, o que pode ser explicado pela grande variabilidade nos valores de APD para determinado AMV. 
Figura 10 - Porcentagem predita de insatisfeitos (PPD) e porcentagem de pessoas insatisfeitas (APD) em função do voto médio predito (PMV) - edificação com sistema de ar-condicionado central; cada ponto representa a média dos votos em cada estudo de campo

- APD

- Curva PMV/PPD

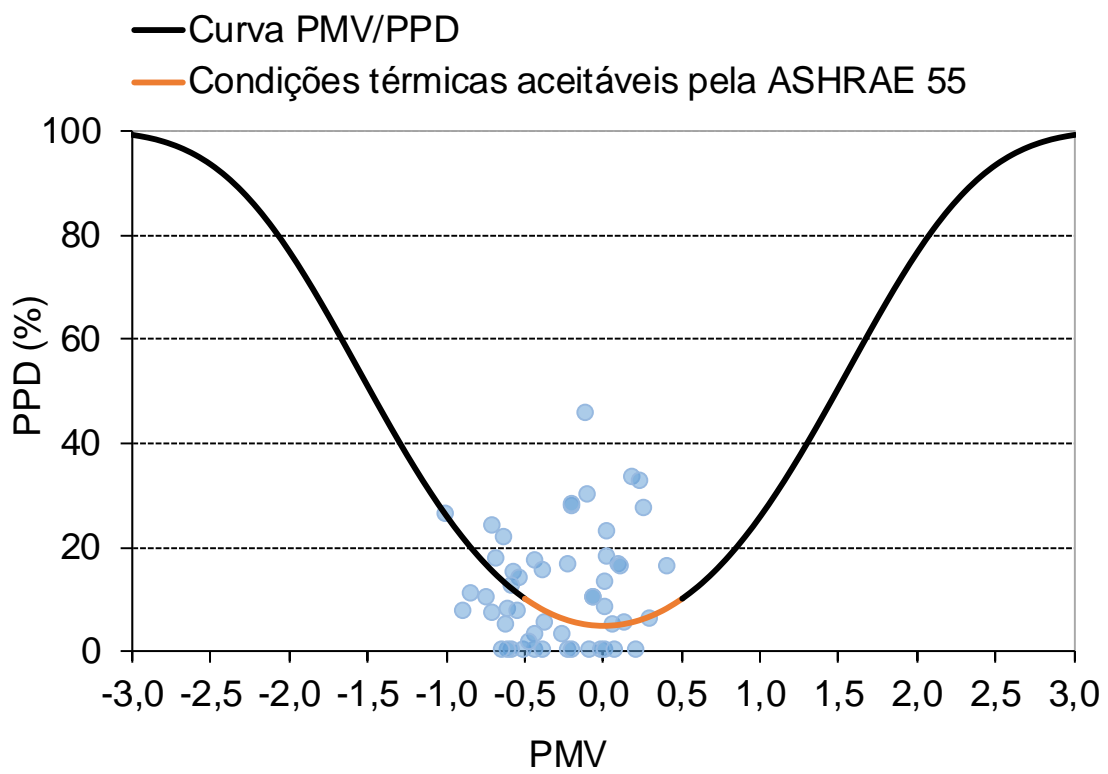

Figura 11 - Porcentagem predita de insatisfeitos (PPD) e porcentagem de pessoas insatisfeitas (APD) em função do voto médio predito (PMV) - edificações com ventilação híbrida; cada ponto representa a média dos votos em cada estudo de campo

-Curva PMV/PPD

—Condições térmicas aceitáveis pela ASHRAE 55

- APD (Ventilação natural)

$\square$ APD (Ar-condicionado)

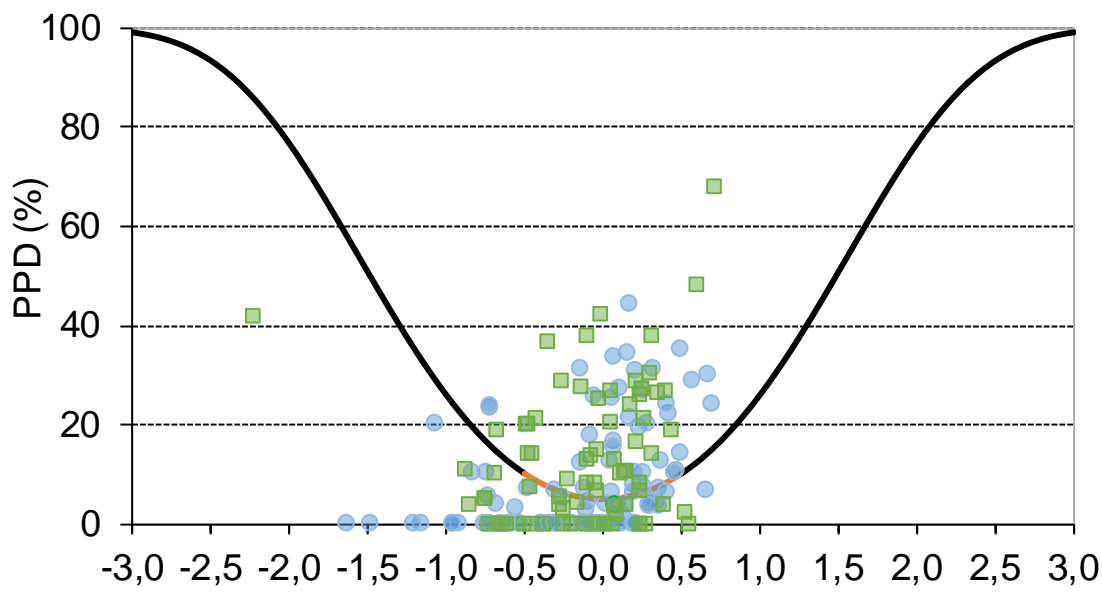

PMV 
Figura 12 - Porcentagem de pessoas insatisfeitas (APD) em função do voto médio de sensação térmica das pessoas (AMV); os dados de todas as edificações estão agrupados - cada ponto representa a média dos votos em cada estudo de campo

- AMVIAPD - - - Curva PMVIPPD

- Curva AMVIAPD

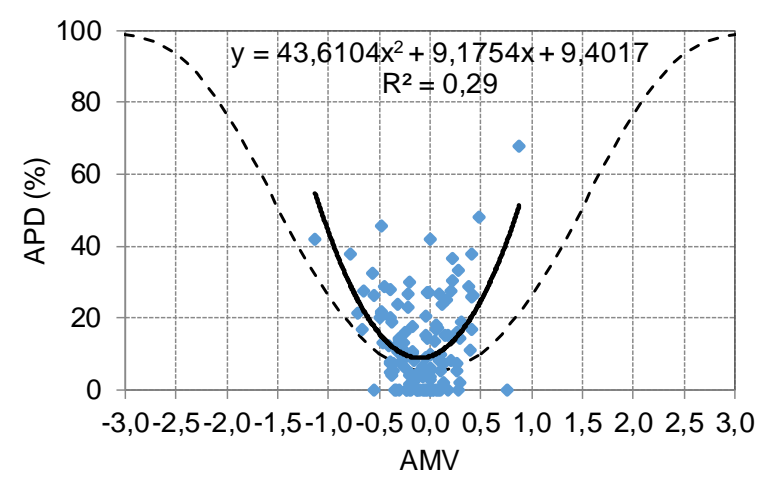

(a) Ar-condicionado

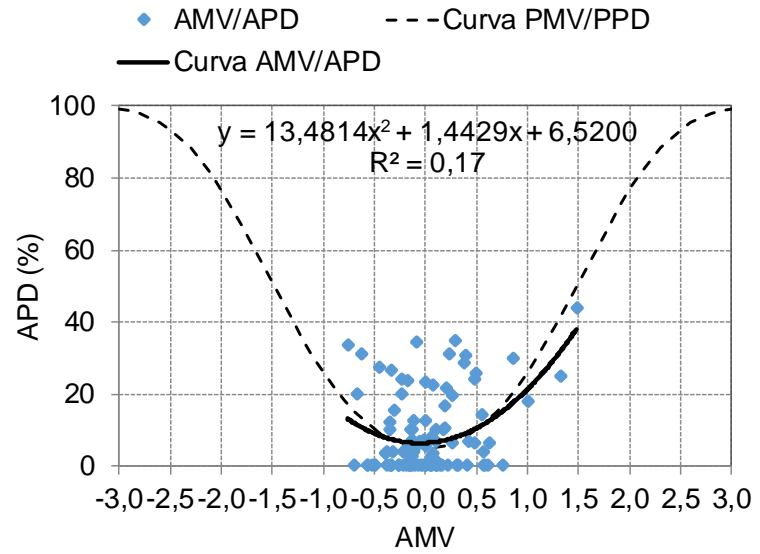

(b) Ventilação natural

\section{Comparação entre as porcentagens real e predita de aceitabilidade térmica}

As temperaturas operativas internas avaliadas como aceitáveis ou inaceitáveis pelos usuários foram comparadas com o modelo adaptativo de conforto térmico da ASHRAE 55 (temperatura de conforto versus temperatura média predominante do ar externo) para a edificação com sistema de arcondicionado central (Figura 13) e para as edificações com ventilação híbrida (Figura 14). A Tabela 5 mostra o resumo das aceitabilidades térmicas preditas (80 e $90 \%$ de aceitabilidade) e reais dos usuários.

Na edificação com sistema de ar-condicionado central, as temperaturas internas foram mantidas em uma estreita faixa, principalmente durante menores temperaturas externas (Figura 13). Considerando a faixa de $80 \%$ de aceitabilidade do modelo adaptativo da ASHRAE 55, 100,0\% dos usuários aceitariam o ambiente termicamente. Porém, a aceitabilidade dos usuários foi de $94,5 \%$, valor mais próximo da aceitabilidade térmica predita considerando a faixa de $90 \%$ de aceitabilidade do modelo adaptativo (98,0\%). Surpreendentemente, observou-se tendência linear nos dados no sentido de quanto maior as temperaturas externas, maiores foram as temperaturas internas. Em contrapartida, analisando-se os resultados obtidos para o modo de ar-condicionado nas edificações com ventilação híbrida (Figura 14a), apesar das temperaturas internas oscilarem em uma faixa mais ampla do que na edificação com sistema de ar-condicionado central, não se observou esta tendência linear entre as temperaturas internas e externas. Novamente, a aceitabilidade térmica predita $(92,0 \%)$ pela faixa de $90 \%$ de aceitabilidade do modelo adaptativo da ASHRAE 55 se aproximou mais da aceitabilidade térmica dos usuários (92,8\%).

Durante o uso da ventilação natural nas edificações com ventilação híbrida, observou-se que as temperaturas internas variaram conforme a temperatura média predominante do ar externo (Figura 14b). A aceitabilidade térmica dos usuários foi de $95,7 \%$, sendo similar à aceitabilidade predita pelo modelo adaptativo da ASHRAE 55 (98,7\% para a faixa de $80 \%$ de aceitabilidade e de $93,7 \%$ para a faixa de $90 \%$ de aceitabilidade). 
Figura 13 - Temperatura operativa interna conforme a temperatura média predominante do ar externo na edificação com sistema central de ar-condicionado

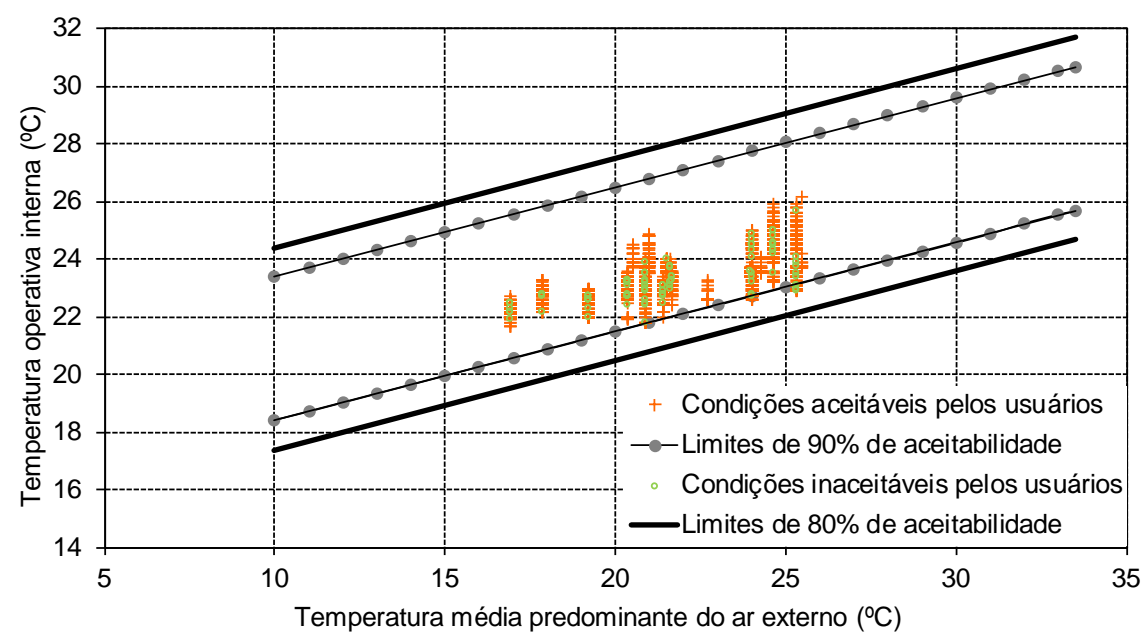

Figura 14 - Temperatura operativa interna conforme a temperatura média predominante do ar externo nas edificações com ventilação híbrida, em função do modo de operação.

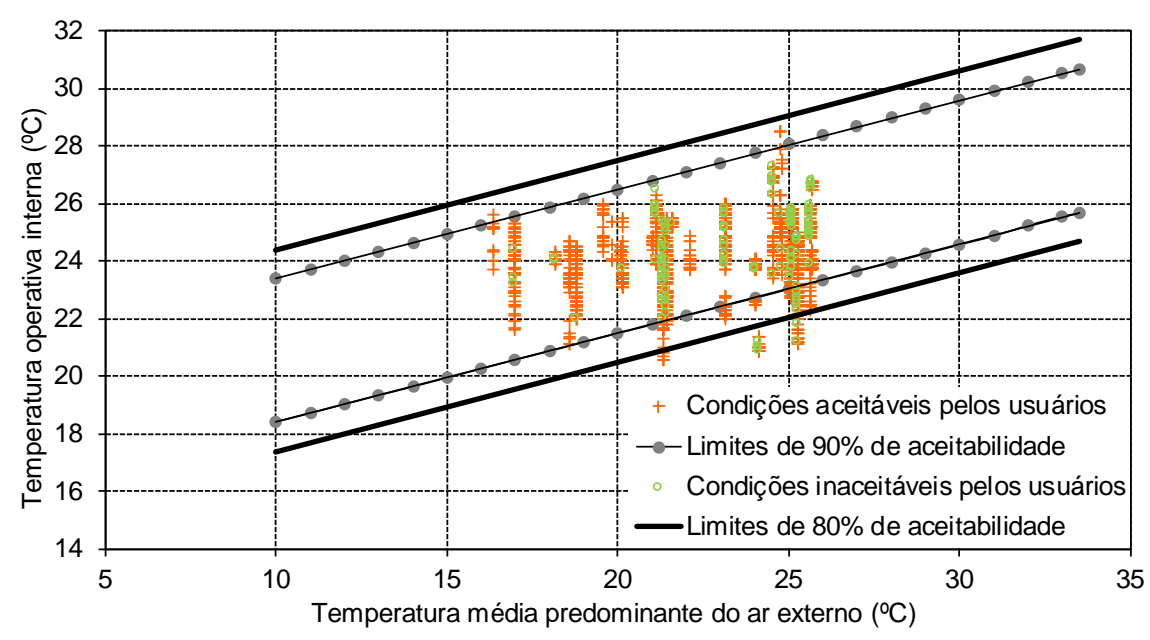

(a) Ar-condicionado

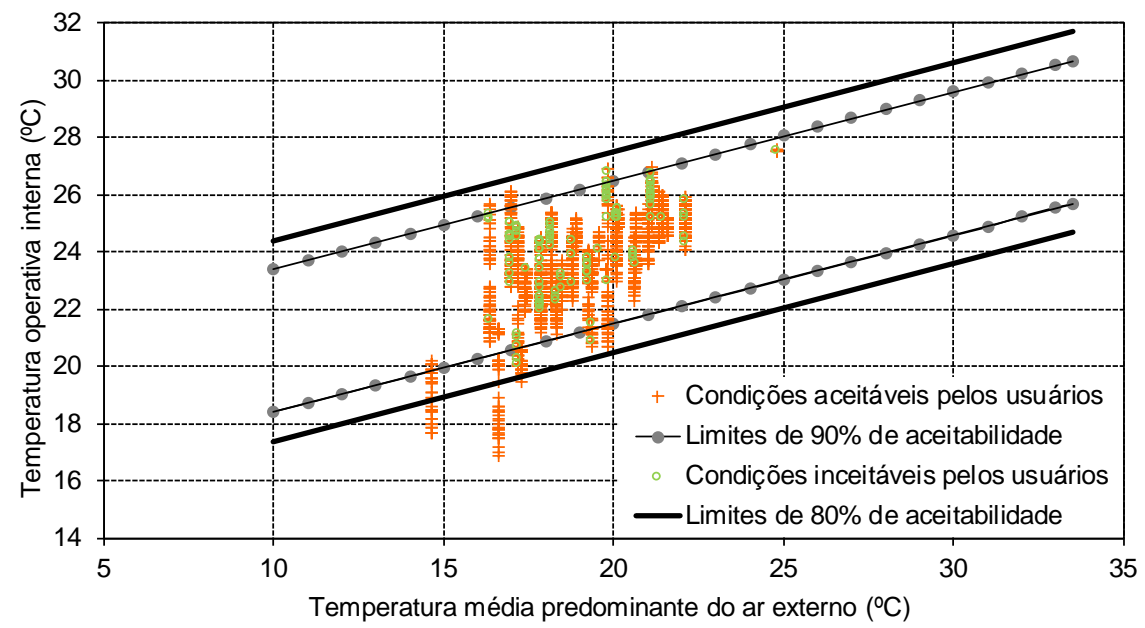

(b) Ventilação natural 
Tabela 5 - Aceitabilidade térmica predita e dos usuários na edificação com sistema de ar-condicionado central e nas edificações com ventilação híbrida

\begin{tabular}{c|c|c|c|c}
\hline \multirow{2}{*}{$\begin{array}{c}\text { Tipo de } \\
\text { ventilação da } \\
\text { edificação }\end{array}$} & \multirow{2}{*}{ Modo de operação } & \multicolumn{3}{|c}{ Aceitabilidade térmica (\%) } \\
\cline { 3 - 4 } & & Modelo adaptativo ASHRAE 55 & \multirow{2}{*}{ Real } \\
\cline { 3 - 4 } & & Limites de 80\% & Limites de 90\% & \\
\hline AC central & Ar-condicionado & 100,0 & 98,0 & 94,5 \\
\hline \multirow{2}{*}{ Híbridos } & Ar-condicionado & 97,1 & 92,0 & 92,8 \\
& Ventilação natural & 98,7 & 93,7 & 95,7 \\
\hline
\end{tabular}

\section{Conclusões}

Por meio da análise dos dados não foram encontradas evidências para justificar as condições térmicas aceitáveis (PMV $\pm 0,5)$ pela ASHRAE 55. Diferentemente dos resultados apontados por outros estudos realizados em escritórios em Florianópolis durante o inverno e o outono (VECCHI, 2015; RUPP; GHISI, 2017), neste trabalho o método PMV superestimou tanto a sensação de frio quanto a de calor dos usuários. O PPD também não estimou adequadamente a porcentagem de insatisfeitos termicamente, em todas as estações climáticas e edificações. Este resultado vai ao encontro de outros trabalhos que compararam PPD e APD no Brasil (LAMBERTS et al., 2013, RUPP; GHISI, 2017) e também em outros locais (HWANG et al., 2009; HENS, 2009). A aceitabilidade térmica predita durante a operação do ar-condicionado foi similar à aceitabilidade real ao considerar-se um intervalo de PMV entre $-1,0$ e $+1,0$. Este resultado é similar ao encontrado por Hwang et al. (2009) para ambientes com sistema de ar-condicionado em Taiwan. Dessa maneira, no clima subtropical úmido brasileiro, esta faixa mais ampla de variação do PMV pode ser utilizada para avaliar o conforto térmico em edificações de escritórios com sistema de ar-condicionado central ou durante a operação do sistema de ar-condicionado em edificações com ventilação híbrida. Essa maior variação nas condições térmicas internas não prejudica o conforto térmico e ajuda a economizar energia em sistemas de ar-condicionado. Outro fator que pode reduzir o consumo de energia, sem comprometer o conforto térmico, é a utilização da estratégia de ventilação híbrida: os resultados deste trabalho indicaram níveis semelhantes de conforto e aceitabilidade térmica em ambos os tipos de ventilação da edificação (ar-condicionado central ou ventilação híbrida).

Neste trabalho, altas porcentagens de aceitabilidade térmica foram obtidas em todas as edificações. A questão sobre aceitabilidade térmica empregou uma escala binária (“Aceitável” ou "Inaceitável”), o que pode ter influenciado nos resultados (SCHWEIKER et al., 2017). Talvez alguns usuários que sentiram certo desconforto térmico, por não terem a possibilidade de assinalar uma eventual opção “moderadamente inaceitável” ou "moderadamente aceitável”, acabaram respondendo “Aceitável” ao invés de "Inaceitável”. Essas diferenças na semântica e nas escalas podem ser aprofundadas em pesquisas futuras.

Os usuários se adaptaram às variações de temperatura interna de acordo com as temperaturas externas (conforme a teoria de conforto térmico adaptativo), principalmente devido ao ajuste de vestimenta, durante o uso da ventilação natural nas edificações com ventilação híbrida. Portanto, o modelo adaptativo pode ser utilizado para avaliar o conforto térmico em edificações de escritórios com ventilação híbrida durante a operação da ventilação natural (a faixa de 90\% de aceitabilidade apresentou resultados mais próximos à aceitabilidade térmica dos usuários). Dessa maneira, a ASHRAE 55 deveria ser revisada, ampliando o escopo de aplicação do modelo adaptativo. Outros trabalhos encontrados na literatura chegaram a conclusões similares (DE DEAR; BRAGER, 2002; LUO et al., 2015; RUPP; DE DEAR; GHISI, 2018). Assim, este trabalho corrobora esta necessidade de revisão da norma americana.

No Brasil há a necessidade da realização de mais estudos de campo nos diferentes climas, em diferentes tipologias construtivas e com populações específicas (jovens, idosos, etc.). Dessa maneira, os modelos de conforto térmico da ASHRAE 55 podem ser estudados em outros trabalhos, bem como a proposição de modelos específicos para o cenário nacional.

\section{Referências}

AMERICAN SOCIETY OF HEATING, REFRIGERATING AND AIR-CONDITIONING ENGINEERS. ANSI/ASHRAE Standard 55:

thermal environmental conditions for human occupancy. Atlanta, 2004.

AMERICAN SOCIETY OF HEATING, REFRIGERATING AND AIR-CONDITIONING ENGINEERS. ANSI/ASHRAE Standard 55:

thermal environmental conditions for human occupancy. Atlanta, 2017. 
ARENS, E. et al. Are “Class A” Temperature Requirements Realistic or Desirable? Building and Environment, v. 45, n. 1, p. 4-10, 2010.

CAO, B. et al. Field Study of Human Thermal Comfort and Thermal Adaptability During the Summer and Winter in Beijing. Energy and Buildings, v. 43, n. 5, p. 1051-1056, 2011.

DAGHIGH, R.; SOPIAN, K. Effective Ventilation Parameters and Thermal Comfort Study of Airconditioned Offices. American Journal of Applied Sciences, v. 6, n. 5, p. 943-951, 2009.

DE DEAR, R. J.; BRAGER, G. Developing an Adaptive Model of Thermal Comfort and Preference. ASHRAE Transactions, v. 104, p. 145-167, 1998.

DE DEAR, R. J.; BRAGER, G. Thermal Comfort in Naturally Ventilated Buildings: revisions to ASHRAE Standard 55. Energy and Buildings, v. 34, p. 549-561, 2002

DEUBLE, M.; DE DEAR, R. Mixed-Mode Buildings: a double standard in occupants' comfort expectations. Building and Environment, v. 54, p. 53-60, 2012.

FANGER, P. O. Thermal Comfort: analysis and applications in environmental engineering. Copenhagen: Danish Technical Press, 1970.

FONG, K. F.; CHOW, T. T.; LI, C. Comfort Zone of Air Speeds and Temperatures for Air-

Conditioned Environment in the Subtropical Hong Kong. Indoor and Built Environment, v. 19, n. 3, p. 375-381, 2010.

HENS, H. S. L. C. Thermal Comfort in Office Buildings: two case studies commented. Building and Environment, v. 44, n. 7, p. 1399-1408, 2009.

HOYT, T. et al. Energy Savings From Extended Air Temperature Setpoints and Reductions in Room Air Mixing. Proceedings of International Conference on Environmental Ergonomics, Boston, 2009.

HUMPHREYS, M. A.; RIJAL, H. B.; NICOL, J. F. Updating the Adaptive Relation Between Climate and Comfort Indoors: new insights and an extended database. Building and Environment, v. 63, p. 40-55, 2013.

HUMPHREYS, M. A.; NICOL, J. F. The Validity of ISO-PMV For Predicting Comfort Votes in Every-Day Thermal Environments. Energy and Buildings, v. 34, p. 667-684, 2002.

HUMPHREYS, M.A.; NICOL, J.F. Understanding the Adaptive Approach to Thermal Comfort. ASHRAE Transactions, v. 104, p. 991-1004, 1998.
HWANG, R.-L. et al. Additive Model For Thermal Comfort Generated by Matrix Experiment Using Orthogonal Array. Building and Environment, v. 44, n. 8, p. 1730-1739, 2009.

\section{LAMBERTS, R. et al. Towards a Brazilian} Standard on Thermal Comfort. 2013.

Disponível em:

$<$ http://www.labeee.ufsc.br/sites/default/files/publi cacoes/relatorios_pesquisa/RP_Towards_a_Brazili an_Standard_Complete_Version.pdf $>$. Acesso em: 02 fev. 2018.

LUO, M. et al. Evaluating Thermal Comfort in Mixed-Mode Buildings: a field study in a subtropical climate. Building and Environment, v. 88, p. 46-54, 2015.

MAITI, R. Physiological and Subjective Thermal Response From Indians. Building and Environment, v. 70, p. 306-317, 2013.

MAITI, R. PMV Model Is Insufficient to Capture Subjective Thermal Response From INDIANS. International Journal of Industrial Ergonomics, v. 44, n. 3, p. 349-361, 2014.

NICOL, F.; HUMPHREYS, M. Derivation of the Adaptive Equations For Thermal Comfort in FreeRunning Buildings in European Standard EN15251. Building and Environment, v. 45, n. 1, p. 11-17, 2010.

NICOL, J. F.; HUMPHREYS, M. A. Adaptive Thermal Comfort and Sustainable Thermal Standards For Buildings. Energy and Buildings, v. 34, n. 6, p. 563-572, 2002.

R CORE TEAM. R: a language and environment for statistical computing. R Foundation for Statistical Computing, Vienna. Disponível em: $<$ https://www.R-project.org/>. Acesso em: 15 jan. 2017.

RICCIARDI, P.; BURATTI, C. Thermal Comfort in Open Plan Offices in Northern Italy: an adaptive approach. Building and Environment, v. 56, p. 314-320, 2012.

RUPP, R. F.; DE DEAR, R.; GHISI, E. Field Study of Mixed-Mode Office Buildings in Southern Brazil Using an Adaptive Thermal Comfort Framework. Energy and Buildings, v. 158, p. 1475-1486, 2018.

RUPP, R. F. et al. Conforto Térmico Humano em Escritórios Com Sistema Central de Condicionamento Artificial em Clima Subtropical Úmido: estudos de campo vs. abordagem analítica. Ambiente Construído, Porto Alegre, v. 17, n. 1, p. 111-123, jan./mar. 2017. 
RUPP, R. F. Conforto Térmico Humano em Edificações de Escritórios Localizadas no Clima Subtropical Úmido de Florianópolis/SC. Florianópolis, 2018. 289 f. Tese (Doutorado em Engenharia Civil) - Programa de Pós-graduação em Engenharia Civil, Universidade Federal de Santa Catarina, Florianópolis, 2018.

RUPP, R.F.; GHISI, E. Predicting Thermal Comfort in Office Buildings in a Brazilian Temperate and Humid Climate. Energy and Buildings, v. 144, p. 152-166, 2017.

RUPP, R.F.; VÁSQUEZ, N.G.; LAMBERTS, R. A Review of Human Thermal Comfort in the Built Environment. Energy and Buildings, v. 105, p. 178-205, 2015.

SCHWEIKER, M. et al. Challenging the Assumptions For Thermal Sensation Scales.

Building Research \& Information, v. 45, n. 5, p. 572-589, 2017.
SILVA, A. S.; GHISI, E.; LAMBERTS, R. Performance Evaluation of Long-Term Thermal Comfort Indices in Building Simulation According to ASHRAE Standard 55. Building and

Environment, v. 102, p. 95-115, 2016.

VAN HOOF, J. Forty Years of Fanger's Model of Thermal Comfort: comfort for all? Indoor Air, v. 18, p. 182-201, 2008.

VECCHI, R. Avaliação de Conforto Térmico em Edificações Comerciais Que Operam Sob Sistemas Mistos de Condicionamento Ambiental em Clima Temperado e Úmido. Florianópolis, 2015. 237 f. Tese (Doutorado em Engenharia Civil) - Programa de Pós-graduação em Engenharia Civil, Universidade Federal de Santa Catarina, Florianópolis, 2015.

\section{Agradecimentos}

Os autores agradecem a CAPES e ao CNPq pelos recursos investidos nesta pesquisa.

\section{Ricardo Forgiarini Rupp}

Departamento de Engenharia Civil, Centro Tecnológico, Laboratório de Eficiência Energética em Edificações | Universidade Federal de Santa Catarina | Trindade | Florianópolis - SC - Brasil | Caixa Postal 476 | CEP 88040-970 | Tel.: (48) 3721-5184 | E-mail: ricardorupp@gmail.com

\section{Enedir Ghisi}

Departamento de Engenharia Civil, Centro Tecnológico, Laboratório de Eficiência Energética em Edificações | Universidade Federal de Santa Catarina | Tel.: (48) 3721-2115 | E-mail: enedir.ghisi@ufsc.br

Revista Ambiente Construído

Associação Nacional de Tecnologia do Ambiente Construído

Av. Osvaldo Aranha, 99 - 30 andar, Centro

Porto Alegre - RS - Brasil CEP $90035-190$

Telefone: +55 (51) 3308-4084 Fax: +55 (51) 3308-4054

www. seer. ufrgs. br/ ambienteconstruido

E-mail: ambienteconstruido@ufrgs.br 